\title{
ANÁLISIS FORMAL DE LA HISTORIA APOLLONII REGIS TYRI
}

\author{
María Victoria Fernández-Savater Martín
}

\author{
(UNED, Madrid)
}

Entre las diversas obras que integran el mundo de la novelística antigua, destaca por su originalidad, no ciertamente por su calidad, la Historia Apollonii regis Tyri ${ }^{1}$. La originalidad de este breve relato es fácil de apreciar tras la lectura de las novelas griegas y latinas ${ }^{2}$ : las diferencias que separan a las unas de las otras son notables y de diversa índole; pues bien, en la línea divisoria, oscilando, se encuentra este singular relato que por un lado parece pertenecer, sobre todo por su temática, a la tradición griega y que sin embargo está en latín.

1 Esta breve novela, de estilo escueto y sencillo, era prácticamente desconocida hace quince años, cuando Carlos García Gual me habló de su existencia y me propuso su estudio como tema para mi tesis doctoral. Últimamente el interés por ella ha aumentado de forma llamativa, y se ha convertido en objeto de numerosos estudios que han engrosado su hasta el momento escasa bibliografía. Ésta es recogida y comentada en mi tesis La Historia de Apollonii regis Tyri. Análisis temático y estructura novelesca, presentada en la UNED, 1993.

2 La «Biblioteca Clásica Gredos» ofrece excelentes traducciones de todas ellas acompañadas de completas y utilísimas introducciones. 
Los datos fidedignos que acerca de ella poseemos son muy pocos por lo que la obra ha sido objeto de todo tipo de especulaciones. De entre todos los juicios sobre ella vertidos, fueron dos, en los que numerosos investigadores insisten, los que me llevaron a realizar este análisis: a) la obra está falta de coherencia y presenta débil motivación interna (cuando gozó de una inusitada popularidad en su historia posterior), y b) parece una novela griega (cuando la estructura de ésta gira alrededor de dos héroes - los jóvenes enamorados que se reparten el protagonismo y las aventuras-).

«Par oú commencer?» ${ }^{3}$. Sin duda tendría que estudiar la estructura del relato, pero qué dirección tomar era sin duda el problema sobre todo teniendo en cuenta las palabras de Barthes: «en análisis estructural no existe un metodo canónico comparable al de la sociología o al de la filosofía, de tal manera que aplicándolo a un texto pueda hacer surgir la estructura» ${ }^{4}$. Unas palabras de Starobinski ${ }^{5}$ vinieron entonces en mi ayuda, y decidí a partir de ellas plantearle al texto en cuestión una serie de preguntas interesadas que le hicieran responderme bajo la forma de una determinada estructura. Necesitaba saber cuál era la espina dorsal que recorre y sustenta la novela; responder a esta pregunta es difícil si tenemos en cuenta la cantidad de materiales que en ella aparecen, pero no es imposible si conseguimos distinguir lo que Aristóteles ${ }^{6}$ llama argumento de los episodios en los que éste se encuentra desarrollado: «En cuanto a los argumentos,... es preciso esbozarlos, en general, entonces y sólo después introducir los episodios y desarrollar [el argumento]" (Poet. 1455b). Seguidamente y para nuestra satisfacción, como tantas veces en su Poética, Aristóteles no se limita a exponer una teoría, sino que nos aclara con un ejemplo, en este caso con la exposición del argumento de Ifigenia y la Odisea ${ }^{7}$.

3 Título de un artículo de Barthes dedicado al análisis estructural, publicado en la revista Poétique 1, (1970).

4 El párrafo pertenece al citado artículo de la revista Poétique.

5 «Las estructuras no son cosas inertes ni objetos estables, surgen a partir de una relación que se establece entre el observador y el objeto, se suscitan en respuesta a una pregunta preliminar, y en función de esta pregunta que se pone a las obras, se establecerá el orden de preferencia de sus elementos descifrados. Al contacto con mi pregunta es cuando las estructuras se manifiestan y se hacen sensibles en un texto fijado hace mucho tiempo en la página de un libro. Los diversos tipos de lectura eligen y sacan del texto las estructuras preferenciales» (Starobinski en respuesta a la encuesta sobre Strutturalismo e critica, p. XIX, ed. Il Saggiatore, Catalogo General 1958-1965)

6 Para las citas de la Poética de Aristóteles empleamos la edición de García Yebra (1974).

7 «En efecto, en la Odisea el argumento no es largo: alguien pasa alejado de su patria muchos años, cuidado por Poseidón y solo, y mientras tanto las cosas en su casa transcurren de tal manera que sus riquezas son consumidas por unos pretendientes y su hijo es objeto de insidias, y él llega tras ser víctima de todo tipo de tempestades y haciéndose reconocer por algunos se lanza al ataque, y él mismo se salva y destruye a los enemigos». 
Esta diferencia que Aristóteles establece entre argumento y episodios es precursora de los modernos sistemas empleados para el análisis de textos narrativos. En cierta forma los acontecimientos que constituyen el argumento de Aristóteles se acercan a lo que serían los motivos ligados $^{8}$ de la fábula en Tomachevsky, o las funciones cardinales ${ }^{9}$ de la historia en Barthes. De estas funciones dice Barthes que son las verdaderas bisagras de la narración. Por su parte, Tomachevsky (1982: 186), asegura que los motivos de una obra pueden ser heterogéneos: «Basta con parafrasear la fábula de una obra para comprender inmediatamente qué es lo que se puede eliminar sin perjudicar la coherencia del relato y lo que, por el contrario, no se puede omitir sin destruir el nexo casual entre los acontecimientos». Estos motivos que no se pueden omitir son los motivos ligados.

Los espisodios de Aristóteles se corresponderían en cierta forma con los motivos libres de Tomachevsky o las catálisis de Barthes ${ }^{10}$.

También Aristóteles nos señalaba la presencia de elementos fundamentales e insuprimibles en la fábula: «la fábula, puesto que es imitación de una acción, lo sea de una sola y entera, y, que las partes de los acontecimientos se ordenen de tal manera que, si se traspone o suprime una parte, se altera y disloque todo, pues aquello cuya presencia o ausencia no significa nada, no es parte alguna del todo» (Poet. 1451a 30-35).

Al hablar de funciones o motivos y de las relaciones y nexos que entre ellas se establecen, tenemos necesariamente que referirnos a otras dos

8 El término motivo es polisémico. El sentido en que Tomachevsky lo usa aquí responde a esta definición: «En la descomposición de la obra en partes temáticas, llegamos por último, a las partes no descomponibles, a las divisiones más reducidas del material verbal... El tema de una parte indivisible de la obra se llama motivo» (1982: 185). Propp (1985), quien estudió rigurosamente los motivos (en el sentido de Tomachevsky), cré́ para ellos el nuevo término de función y la definió como «lo realizado por un personaje determinado desde el punto de vista de su significado para el desarrollo de la intriga» (1985: 32). No se trata ahora del motivo literario, elemento recurrente en una obra o en varias. El mismo Tomachevsky (1982:185-186) aclara que «el término motivo empleado por la poética histórica en el estudio comparativo de las tramas «errantes»,... es sustancialmente distinto de la acepción aquí adoptada... En el análisis comparativo de los motivos, se define como motivo una unidad temática que se repite en diversas obras». Sobre esta acepción de motivo cf. Kayser, 1978: 75-78, y Segre, 1985: 339-366.

9 Barthes (1974: 20), distingue dos tipos de funciones, las cardinales que constituyen el verdadero nudo del relato y las catálisis que llenan el espacio narrativo que separa las funciones-nudo. Estas funciones tienen como correlato unidades del mismo nivel, son funciones distribucionales. Existen otras funciones, que Barthes denomina integradoras, y que adquirirán todo su sentido, su funcionalidad, en un nivel superior, en el nivel del discurso.

${ }_{10}$ Motivos libres son aquellos que se pueden eliminar sin perjudicar la integridad de la relación causal-temporal de los hechos (Tomachevsky, 1982: 186). Las catálisis no hacen sino «rellenar» el espacio narrativo que separa las funciones bisagra. 
estructuras que emergen ante nosotros y son, como los conceptos anteriores, objeto de estudio de la narratología: la fábula y la trama ${ }^{11}$.

La trama es la exposición de los acontecimientos narrados en el orden en que se encuentran en el texto. La fábula es la exposición de los mismos acontecimientos en orden cronológico y lógico ${ }^{12}$.

\section{ANÁLISIS}

\subsection{Método de análisis}

Todorov basándose en esta división en dos nociones, propone un estudio de la obra literaria en dos grandes niveles: el nivel de la historia que comprende la lógica de las acciones y una sintaxis de los personajes, y el nivel del discurso que abarca los tiempos, los aspectos y los modos del relato.

Estos dos términos designan pues dos planos diferentes en el análisis de la obra literaria, aunque ambos están íntimamente relacionados, y es precisamente el estudio de la relación entre los dos planos, la que dará mayor sentido a un análisis. Sin embargo, en este momento de nuestro estudio y guiados por la finalidad concreta de determinar esa espina dorsal, ese esqueleto de la obra, en resumidas cuentas: el argumento de Aristóteles y la lógica interna que rige el relato, nos moveremos en el plano de la fábula ${ }^{13}$. Pero es que además queremos determinar también los personajes que, como señala Tomachevsky (1982: 204), enlazan los diversos motivos; observaremos entonces en qué persona$\mathrm{je} / \mathrm{s}$ se agrupan un mayor número de acontecimientos o, de nuevo en palabras de Tomachersky, a qué personaje pertenecen los motivos. A la vez nos será posible apreciar las relaciones entre los personajes, las coincidencias espaciales a las que Bajtin concede tanta importancia en

11 Los primeros en separar las dos nociones fueron los formalistas rusos. Estas estructuras son designadas con diferentes términos: fábula y trama (Tomachevsky), historia y discurso (Todorov), historia y relato (Genette), fábula e historia (Bal).

12 «La fábula es un conjunto de motivos en su lógica relación causal-temporal, mientras que la trama es el conjunto de los mismos motivos, en la sucesión y en la relación que se presentan en la obra» (Tomachevsky, 1982: 186).

13 Pese a nuestra intención inicial, en ocasiones nos es difícil determinar con seguridad en cuál de los niveles nos movemos y si estando en uno hemos invadido el otro. Esto al menos nos servirá para constatar fehacientemente la fortísima interrelación entre ambos niveles. 
el cronotopo de las novelas antiguas ${ }^{14}$. Finalmente veremos el tiempo que cada uno permanece en la fábula y en la trama. Todo ello nos llevará a localizar al héroe ${ }^{15}$.

Intentando conseguir estos objetivos emprendemos un análisis que sabemos es personal, pero que no es finalmente más que el resultado de una reflexión detenida sobre los métodos de análisis del relato propuestos por eminentes estudiosos ${ }^{16}$.

\subsubsection{Explicación de nuestro método de análisis}

1) Pretendemos caracterizar, entre todos los acontecimientos 17 narrados, aquellos que constituyen la estructura de la fábula.

2) Escogeremos los acontecimientos narrativamente determinantes, tal como se pueden deducir del texto una vez eliminados los no determinantes, e indicaremos la relación de causalidad entre ellos.

14 Cf. Bajtin (1989: 250 y ss.).

15 Mucho se ha discutido acerca de la figura del héroe y su definición. Se ha apuntado como criterio de elección del héroe la capacidad del lector para identificarlo. Pero ésta difiere mucho de un lector a otro. Sobre la caracterización del héroe cf. Tomachevsky (1982: 204-207).

Bal (1987: 100) propone para distinguir al héroe observar si sobresale del modo siguiente:

- Calificación: Información externa sobre la apariencia, la psicología, la motivación y el pasado.

- Distribución: El héroe aparece con frecuencia en la historia, su presencia se siente en los momentos importantes de la fábula.

- Independencia: El héroe puede aparecer sólo o tener monólogos.

- Función: Ciertas acciones sólo le competen al héroe: llega a acuerdos, vence a oponentes, desenmascara a traidores, etc.

- Relaciones: Es el que más relaciones mantiene con los otros personajes.

Si atendemos a estos aspectos, evidentemente, en nuestra novela el personaje Apolonio sobresale en todos ellos sobre los demás con mucha diferencia. No hay ningún otro personaje que se le pueda comparar en presencia, relaciones con los demás actores, intervenciones en solitario y asunción de funciones propias de un personaje central.

${ }_{16}$ Las influencias más sobresalientes se aprecian a simple vista, otras de las que ya ni siquiera yo soy consciente, sin duda están ahí. Ya he hablado de Aristóteles, de Tomachevsky (1982) y Barthes (1974), fuentes inagotables de ideas. Junto a ellos están las lecturas de Propp (1985), Bremond (1966) y Hendricks (1973), siguiendo a los cuales esbocé análisis parciales o totales de esta novela. Me interesaron también los modelos actanciales, sobre todo de Greimas (1966) por la importancia que conceden a la actuación de los personajes. Finalmente, $\mathrm{Bal}$ (1987) y su apertura a diferentes formas de análisis fue un gran estímulo

17 Para designar hechos y acciones, que son el objeto principal del análisis de textos narrativos, emplearemos el término acontecimientos tomado de Aristóteles, porque nos parece que engloba bien los dos anteriores. 
3) Distinguiremos entre las sucesiones post hoc y propter hoc que ya indica Propp, así como la causalidad post hoc ergo propter hoc de la que habla Barthes ${ }^{18}$.

4) Los acontecimientos determinantes estarán expresados por una serie de frases-núcleo, de paráfrasis ${ }^{19}$.

5) Especificaremos en todo momento el personaje o personajes relacionado/s con los acontecimientos.

6) La presencia de los personajes en la fábula y en la trama quedará reflejada en el esquema.

7) Por último agruparemos los acontecimientos en lo que vamos a llamar bloques narrativos que actuarán a modo de secuencias ${ }^{20}$, y les daremos una denominación ${ }^{21}$.

\subsection{Esquema de acontecimientos}

Las páginas siguientes recogen en un esquema los acontecimientos que consideramos principales, los personajes protagonistas de ellos y

18 Barthes cuando habla de sus causalidades señala que en las narraciones se generaliza una especie de post hoc, ergo propter hoc: «...el resorte de la actividad narrativa es la confusión misma entre la secuencia y la consecuencia, dado que lo que viene después es leído en el relato como causado por; en este sentido el relato sería una aplicación sistemática del error lógico denunciado por la Escolástica bajo la fórmula post hoc, ergo propter hoc, que bien podría ser la divisa del Destino, de quien el relato no es en suma más que la «lengua» (Barthes, 1974: 20). Según Segre (1985:128), muchas veces una sucesión de hechos es interpretada casualmente por nuestro instinto (compartido y aprovechado por el escritor) para explicar lo que en rigor no es explicable.

19 «La paráfrasis prohibida para el contenido linguiístico de una frase, ... se convierte en un instrumento indispensable para describir los contenidos textuales» (Segre, 1985: 107). «Frente a una acción verbal narrada, en forma verbal o de cualquier otro modo, el crítico y el linguista no pueden sino repetir la acción llevada a cabo por cualquier oyente o lector: reformular o «sumariar» mentalmente el contenido del discurso narrativo. Se producen así reformulaciones metanarrativas, en sustancia, paráfrasis... se intentará reducir al máximo la arbitrariedad de dichas paráfrasis, pero no se puede encontrar medio más objetivo para caracterizar las acciones» (Segre, 1985: 300). Cf. Hendricks (1973), Essays on Semiolonguistics and Verbal Art, Mouton, La Haya, París.

20 Con este concepto se refiere Propp (1985: 121) a la sucesión de funciones que componen un cuento simple o cuento de una sola secuencia. Barthes (1974: 25), siguiendo a Bremond (1974), la define como una sucesión lógica de núcleos unidos entre ellos por una relación de solidaridad.

21 «La secuencia es, en efecto, siempre nombrable... es posible imaginar que forman parte de un metalenguaje interior al lector..., el cual capta toda sucesión lógica de acciones como un todo nominal...: la lógica cerrada que estructura una secuencia está unida a su nombre indisolublemente» (Barthes, 1974: 26). 
lo que hemos llamado su línea temporal. Se señalan también los acontecimientos que pensamos son causados por iniciativa, fortuna o acontecimiento/s precedente/s y los que ocurren en acción paralela.

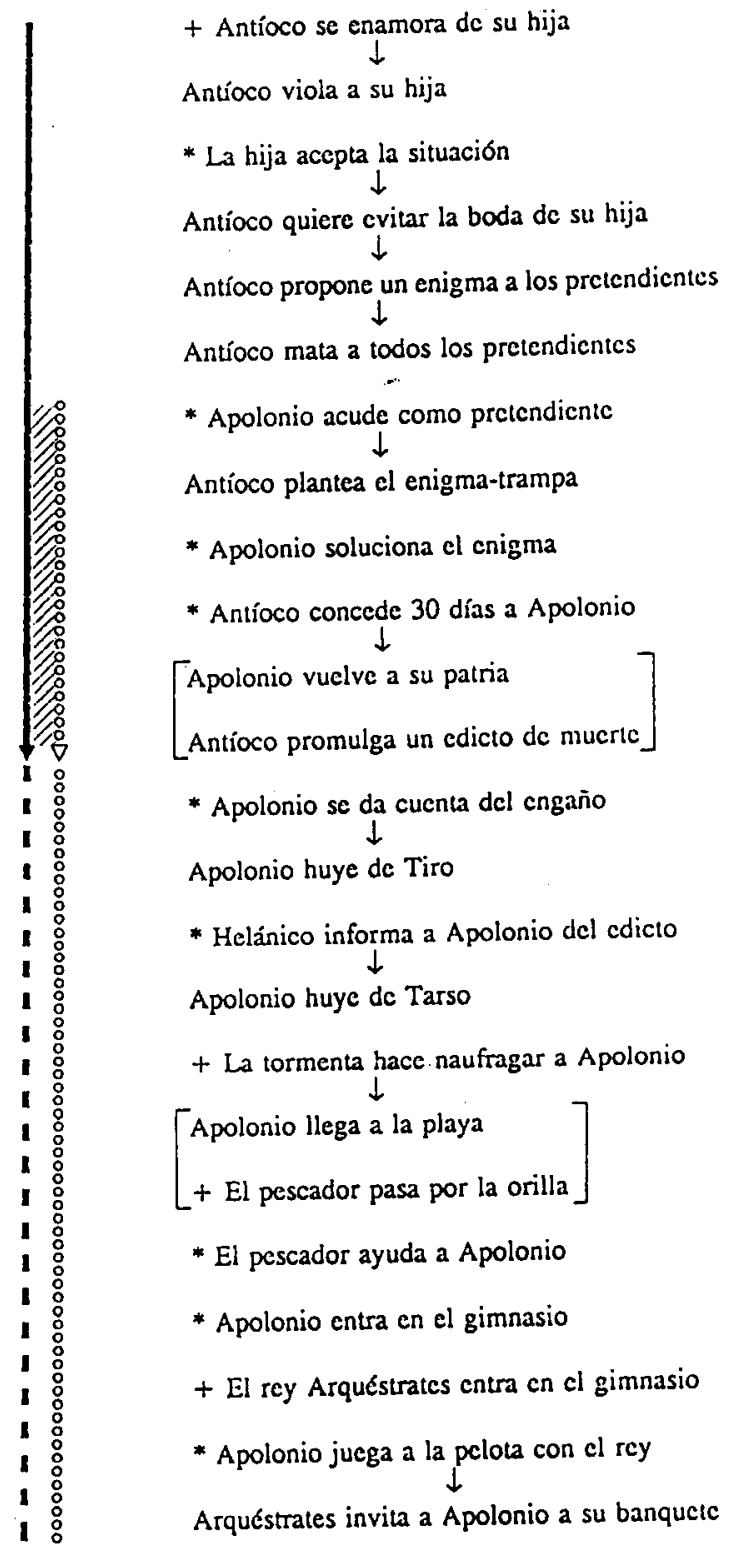




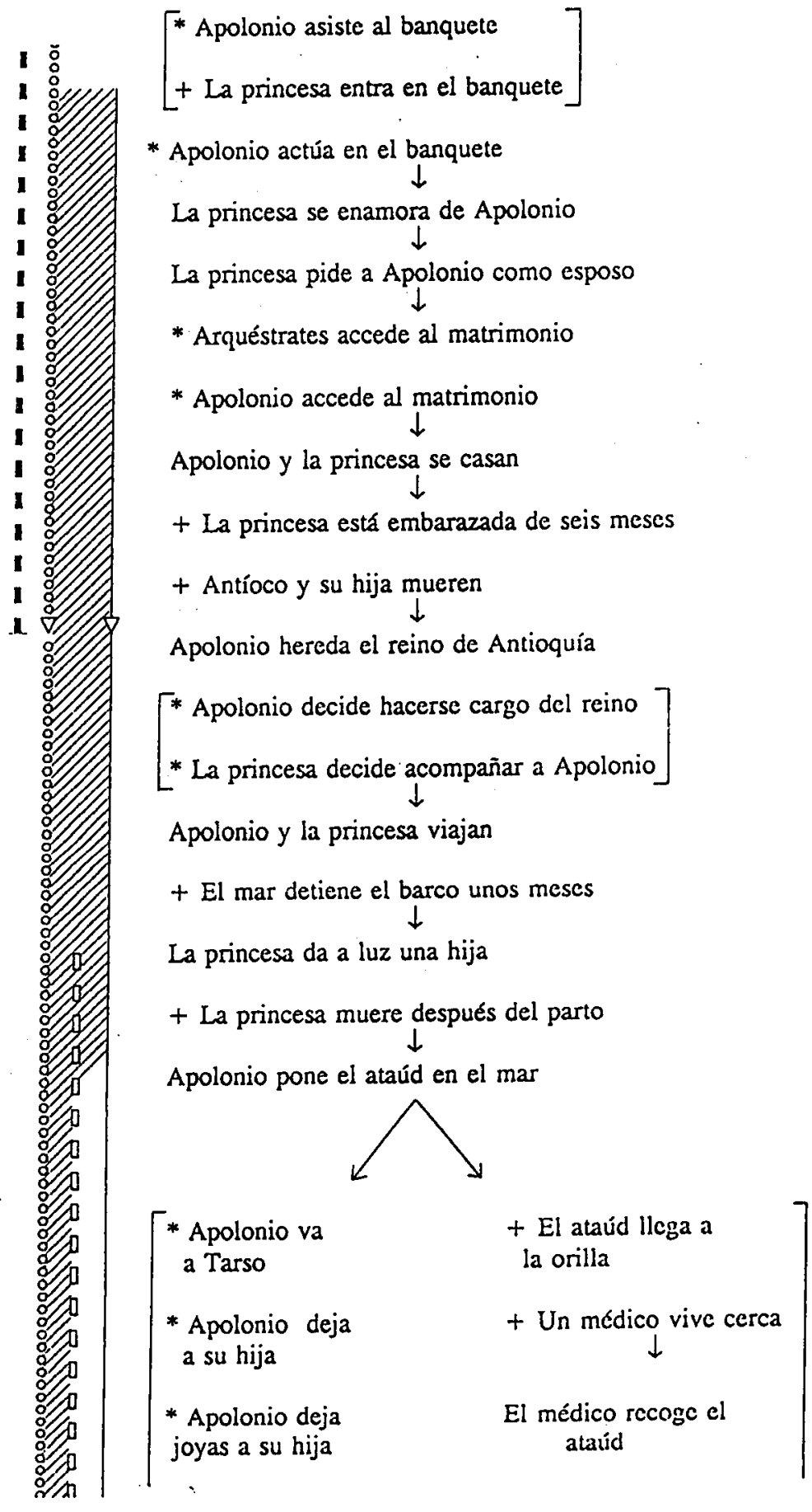




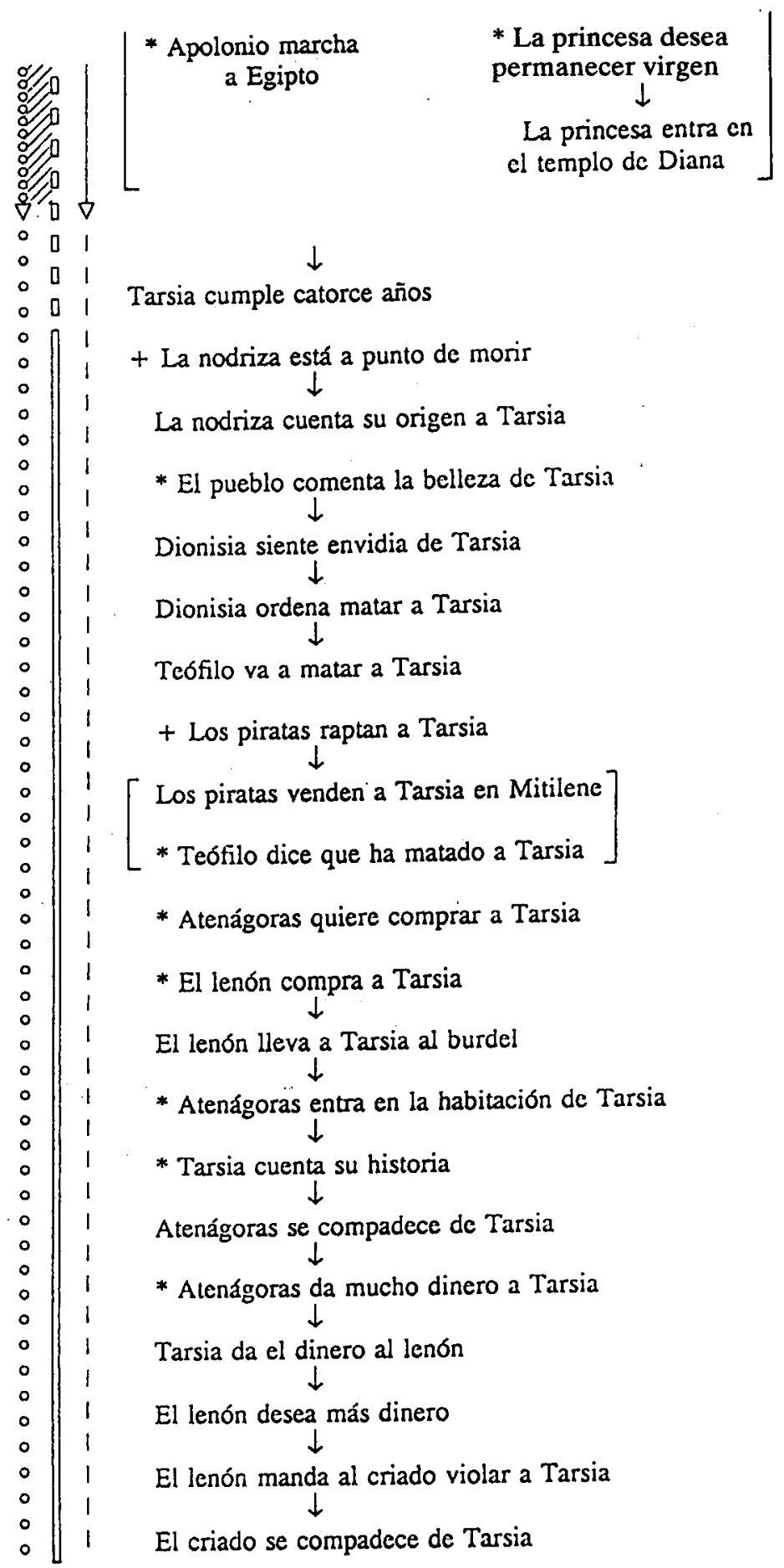




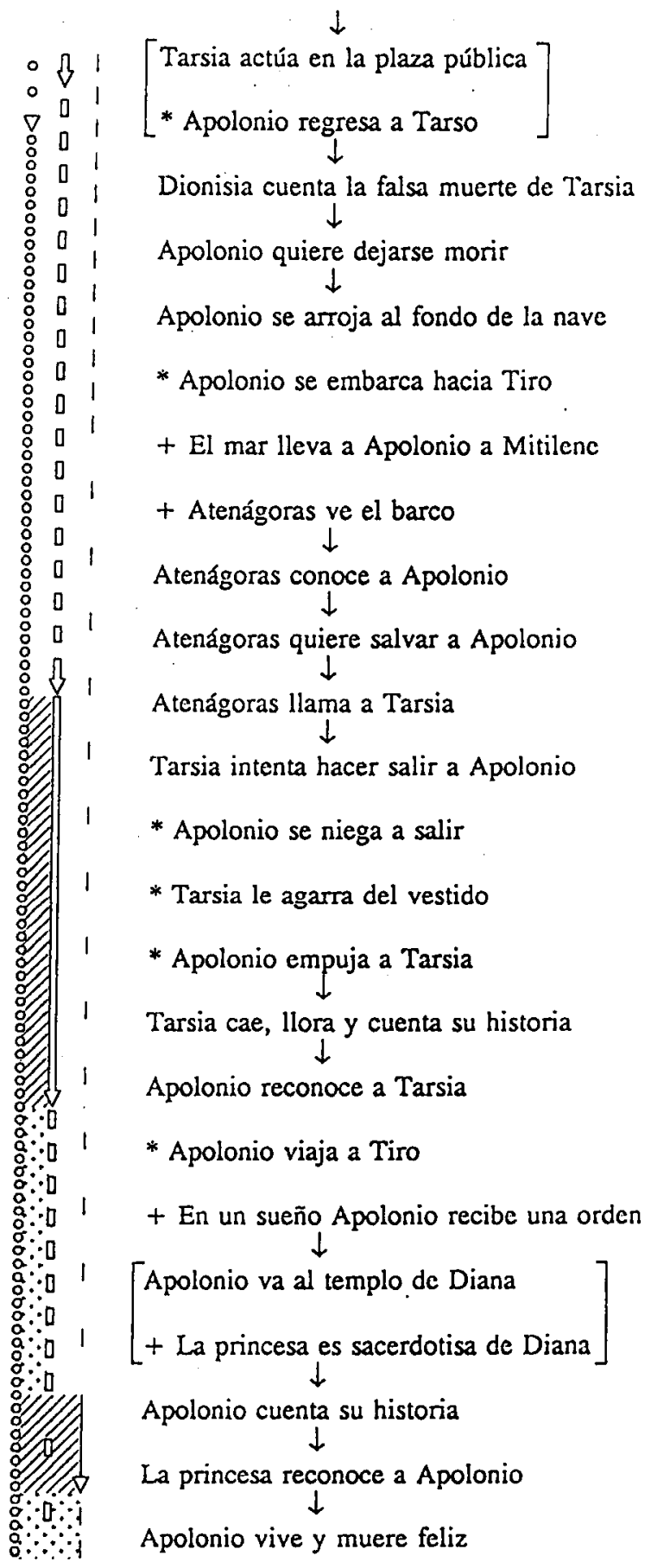




\section{Antíoco}

00000000000 Apolonio

La princesa

Tarsia

* Iniciativa

+ Fortuna

$\downarrow$ Consecuencia del (los) acontecimiento(s) precedente(s)

[ ] Acción paralela

El signo de cada personaje equivale a su presencia en la fábula.

Cuando el signo de un personaje se hace discontinuo significa que éste permanece en la fábula, pero no está presente en la trama.

Las líneas transversales indican la coincidencia espacial de los personajes.

\subsubsection{Comentario del esquema}

Hemos seleccionado noventa y siete acontecimientos, de los que:

1. Cuarenta y seis están causados directamente por un(os) acontecimiento(s) anterior(es).

2. Cincuenta se deben a la iniciativa de los personajes o a la fortuna. En este grupo,

a) treinta y cuatro acontecimientos pueden enmarcarse en lo que llamamos iniciativa y

b) quince, son totalmente fortuitos.

Los acontecimientos seleccionados son esenciales para la fábula, sin ellos se rompería la integridad, el nexo casual entre los hechos. Entre 
estos acontecimientos la mayoría hacen avanzar la acción y la modifican. En menor número aparecen otros que no tienen consecuencias inmediatas en la historia, pero resultan determinantes en otro momento de su desarrollo. Estos dos tipos de acontecimientos se corresponderían con los llamados motivos ligados dinámicos y ligados estáticos de Tomachevsky (1982:188) ${ }^{22}$.

\section{A) Acontecimientos que no tienen una repercusión inmediata en la acción:}

1) La princesa está embarazada de seis meses. Este suceso mostrará su fuerza con el desarrollo de la historia, cuando al detenerse el mar, la princesa cumpla su período de gestación y dé a luz.

2) La princesa entra como sacerdotisa en el templo de Diana. La importancia de esta acción de la princesa la veremos cuando se produzca el reconocimiento de los esposos en el templo.

3) Apolonio deja a su hija en Tarso con riquezas. Después sabremos que los ricos ornamenta de Tarsia darán lugar a la envidia de Dionisia, principio de las desgracias de la joven.

4) Tarsia cumple catorce años. Este suceso justifica el que a Tarsia le ocurran una serie de aventuras que no hubieran sido posibles a otra edad.

5) Tarsia es educada en las artes liberales. Su cultura le permitirá salvarse de la vida del burdel y reencontrarse más tarde con su padre.

6) La nodriza cuenta su origen a Tarsia. Información decisiva para el desenlace de la novela: el reencuentro de padre-hija.

7) Teófilo dice que ha matado a Tarsia. Así se lo hará saber Dionisia a su padre, quien decidirá dejarse morir.

8) Atenágoras entrega mucho dinero a Tarsia. Esta acción estimulará la avaricia del lenón, que mandará violar a Tarsia.

9) Apolonio quiere dejarse morir y se arroja al fondo de la nave. La actitud negativa y autodestructiva del héroe harán que Atenágoras llame a Tarsia para que intente sacarlo de su encierro.

22 Tomachevsky afirma que los motivos estáticos suelen ser libres, pero que no todos los motivos estáticos son libres. Esto se hace evidente en nuestro texto. 


\section{B) Acontecimientos con una repercusión inmediata en la acción}

El resto de los acontecimientos tienen una repercusión inmediata en la acción. Sin embargo, hemos de distinguir entre los acontecimientos que están causados directamente por los anteriores (sucesión propter hoc) y los que se deben a iniciativas de los personajes o a la intervención de la fortuna (sucesión post hoc). Entre estos últimos algunos estarán justificados por los acontecimientos anteriores, por convención del género o por motivaciones psicológicas.

a) Los acontecimientos que están directamente causados por los anteriores quedan reflejados en el esquema por una flecha negra y son fácilmente detectables, por tanto no los comentaremos. Tan sólo vamos a detenernos en uno de ellos que nos parece de singular importancia: después de la muerte de Antíoco, el reino de Antioquía lo hereda Apolonio.

No se trata esta herencia de ningún golpe de fortuna, el acontecimiento está presentado como algo lógico, y es que se está dando aquí la motivación que Barthes definía como post hoc ergo propter hoc, es decir, una serie de hechos concatenados son interpretados por nuestro instinto como causa de algo, y el escritor se aprovecha de ello. El lector ha visto a Antíoco prometer la mano de su hija al que acierte el enigma, ha visto a Apolonio descifrarlo y ha asistido impotente al injusto y criminal comportamiento del rey para con el héroe, que le ha negado lo que le pertenecía. Ahora que el rey ha muerto ha de devolverse a Apolonio lo que es suyo.

El hecho de que Apolonio herede el trono tiene una apariencia de verosimilitud que le concede el contexto en el que se produce; el lector sabe que en justicia Apolonio tendría que haberse casado con la princesa, pero no sólo lo sabe él, el cuento nos ofrece ejemplos de que todo el mundo parece conocer la relación prohibida de Antíoco y no es extraño que conozca también el motivo de la persecución de la que es objeto el héroe. Así pues el lector no considera esta herencia sorprendente, más bien se le antoja justificada por los sucesos anteriores.

b) Acontecimientos causados por iniciativa: Aparecen en el esquema señalados por un asterisco negro. Hemos seleccionado como causados por iniciativa aquellos acontecimientos que dependen de la voluntad del héroe más que de otra cosa. El origen de estas opciones tendremos que buscarla en el nivel siguiente, donde los personajes aparecen caracterizados de una $u$ otra forma. La personalidad que el autor les 
atribuya influirá en sus decisiones. Nos limitaremos a comentar tan sólo una muy peculiar y discutida iniciativa:

Antíoco concede treinta días a Apolonio. Antíoco, se nos dice en el texto, mataba a todos los pretendientes, acertasen o no. La inverosimilitud de esta iniciativa hemos de buscarla en las circunstancias que rodean esta decisión: Apolonio nos ha sido presentado como pretendiente excepcional y es al primero al que hemos visto, realmente, en una escena, resolver el enigma. La falta de lógica en este momento del relato sólo puede justificarse teniendo en cuenta las expectativas ${ }^{23}$ del público. «Toda introducción de motivos es un compromiso entre esta verosimilitud objetiva y la tradición literaria. A causa de su carácter tradicional, no nos damos cuenta de la incongruencia, respecto a la realidad, de la introducción tradicional de motivos», dice Tomachevsky (1982: 197). En la novela de aventuras la salvación del héroe en el último momento es habitual, el lector acepta la concesión de 30 días para que pueda continuar su aventura.

c) Acontecimientos causados por la fortuna ${ }^{24}$. La representación más evidente de la fortuna la constituyen los cambios de humor del mar (al que en nuestro análisis tratamos como a un personaje) y la visión de quendam angelico habitu, que hace las veces de un deus ex machina.

Una intervención más sutil de la mano divina se aprecia en el castigo que sufre Antíoco. La muerte del malvado es providencial y respondería a ese elemento maravilloso del que hablaba Aristóteles, hechos que se producen contra lo que se espera, unos a través de otros, «pues así será más maravilloso que si vinieran de una forma automática y por azar, pues que también de las cosas que ocurren por azar nos parecen más maravillosas las que parece que se han producido a propósito» (Poet. 1452b). La muerte de Antíoco y su hija fulminados por un rayo, es sin duda algo maravilloso que tiene todo el aspecto de haber producido a propósito, como un merecido castigo divino que ya se hacía esperar.

23 Jauss (1976) considera que la obra de arte se inscribe en un sistema complejo de necesidades, expectativas, gustos, lecturas... que constituyen lo que él llama «el horizonte de expectativas» del público. Por una serie de precondicionamientos bastante diversos el lector se «forma una idea» del libro y lo decodifica de acuerdo con algunos estereotipos.

24 La fortuna como tal aparece raras veces en la novela, por eso lo que interpretamos aquí como fortuna es la intervención del suceso de Bajtín: «Todos los momentos del tiempo de la aventura están dirigidos por una sola fuerza: el suceso...» El tiempo del «suceso» de la aventura es el tiempo específico de la intervención de las fuerzas irracionales en la vida humana;...» (1989: 247). 


\subsection{Bloques narrativos}

Entendemos el bloque narrativo como un conjunto de acontecimientos en sucesión lógica y ligados por una unidad temática. En ocasiones dentro de estos bloques podremos encontrar otros más pequeños a modo de microsecuencias. Tomachevsky asegura que «la novela, como gran forma narrativa, no es en general más que la unión de varios cuentos». Nosotros intentaremos delimitar estos «cuentos» y les daremos un nombre. Trataremos a la vez de determinar la sintaxis entre los diferentes bloques y microbloques, y de qué forma se imbrican en la historia principal.

\section{A) El incesto}

Se abre el bloque con el enamoramiento de Antíoco y se cierra, muy avanzada ya la fábula, con la muerte de Antíoco y la princesa por el rayo.

Siguiendo a Bal (1987: 40) podríamos interpretar este bloque como una subfábula dentro de la fábula. Esta historia es anterior a la fábula principal y en ella el hilo de la acción es conducido por un falso héroe, es una presentación anticipada del oponente que dificultará la tarea del verdadero héroe.

Cuando este bloque aún no ha terminado, parte de los acontecimientos que lo integran se imbrican en el siguiente del que son inicio:

\section{B) La prueba}

Antíoco propone una prueba a los pretendientes y Antíoco mata a todos los pretendientes.

Esta secuencia termina cuando Apolonio se va a su patria y, en acción paralela, Antíoco promulga un edicto de persecución.

La unión entre esta secuencia y la siguiente es ante todo actancial ${ }^{25}$. Tomachevsky señala como procedimiento típico de unión entre cuen-

25 «La imbricación de las secuencias no puede, en efecto, cesar dentro de una misma obra, por un fenómeno de ruptura radical. A menos que los bloques estancos, 
tos el de narrarlos ligándolos a un héroe (1982: 258). La coincidencia espacial de los personajes revela la aparición del héroe y la conversión del falso héroe en oponente.

\section{C) La huida}

Este bloque es amplísimo: se abre con Apolonio se da cuenta del engaño y termina con el anuncio de la muerte de Antioco.

Es posible distinguir dentro de este bloque otros más pequeños:

C.1. La persecución: Apolonio huye de Tiro hasta Apolonio huye de Tarso. El viaje que supone la huida de Tarso y el personaje de Apolonio lo enlazan al siguiente bloque.

C.2. El naufragio. La secuencia se abre con: la tormenta hace naufragar a Apolonio y se cierra con la asistencia de Apolonio al banquete.

La unión de ambos bloques es espacial y actancial: la coincidencia de los personajes lleva al encuentro. El último acontecimiento del bloque es inicio del siguiente.

C.3. El encuentro. Se inicia con: la princesa entra en el banquete y termina con el matrimonio de Apolonio y la princesa. Otra vez los personajes son lazo de unión entre los bloques.

\section{D) La separación}

Este bloque queda unido al anterior por el acontecimiento Antíoco y su hija mueren, que cierra el bloque Incesto, y por el anuncio de que el reino de Antíoco corresponde a Apolonio. Dentro de él podemos encontrar tres microbloques:

D.1. La muerte aparente. Se inicia con: Apolonio decide ir a por el reino que le pertenece y termina cuando Apolonio entrega el cuerpo de

que en este caso la componen, sean recuperados al nivel superior de las acciones (de los personajes)" (Barthes, 1974: 28). Sigue diciendo Barthes que los estemmas funcionales pueden dejar de comunicarse, pero subsistir entre ellos una relación actancial, pues los personajes, y por tanto, la estructura de sus relaciones, son los mismos. 
su esposa al mar. En este momento la línea de acción se bifurca en dos bloques y la fábula se hace doble ${ }^{26}$ :

D.2. La resurrección y D.3. El abandono, son dos bloques que se producen al mismo tiempo, en acción paralela. La unidad actancial se conserva en ambos bloques, pero cada uno de ellos tiene como protagonista a un personaje distinto.

D.2. La resurrección. De nuevo nos encontramos aquí con una subfábula: la atención se desplaza hacia otro personaje. Esta subfábula, en la que se cuenta la suerte que corre la princesa que aparentemente muerta ha sido arrojada al mar, está perfectamente integrada en la acción: se inicia en el bloque narrativo anterior cuando la princesa muere y su cuerpo es entregado al mar, y tiene su desenlace varias secuencias más adelante, dentro de la fábula principal que tiene como objeto de atención a Apolonio, cuando se produzca el reencuentro de ambos esposos.

D.3. El abandono. Esta microsecuencia tiene como protagonista a Apolonio. De nuevo la entrega de cuerpo al mar será el inicio, el final Apolonio marcha a Egipto. El héroe desaparece del relato pero, claro está, continúa en la fábula. Este bloque narrativo enlazará después con otro: el regreso, cuando Apolonio retome el hilo de la acción, y tendrá su desenlace en el reencuentro de Apolonio y Tarsia. El bloque es a su vez inicio de la próxima subfábula.

\section{E) Historia de Tarsia}

La historia de Tarsia comienza en el bloque narrativo anterior cuando el padre abandona en Tarso a su hija y se va a Egipto, y terminará integrándose en el relato principal que tiene como protagonista a Apolonio cuando se produzca el reencuentro entre padre e hija. De nuevo estamos ante una subfábula en la que un héroe distinto del de la fábula principal, que hasta ahora tan solo estaba esbozado, toma cuerpo y durante un tiempo conduce la historia.

26 En las obras dramáticas, cuya duración limitada no ofrece la posibilidad de introducir largas sucesiones de hechos, para aumentar el interés, que se debilitaría con una sola línea de fábula, se introducen una o varias vetas narrativas paralelas. «Así, en lugar de dar el desarrollo consecutivo de los motivos, la estructura dramática recurre, frecuentemente, a la elaboración paralela de una fábula compleja» (Tomachevsky, 1982: 219). 
A partir de aquí podemos distinguir en este relato una serie de bloques narrativos más pequeños:

E.1. La verdad. Este breve bloque tan sólo comprende:

la nodriza está a punto de morir y

la nodriza cuenta su historia a Tarsia.

Este bloque no tiene un valor inmediato en la historia; sin embargo, introduce elementos que serán definitivos para el desenlace de la fábula principal.

El personaje Tarsia une este bloque con el siguiente con ayuda del motivo de las joyas que por fin libera toda su fuerza.

E.2. La madrastra. Este bloque se abre con un acontecimiento de una microsecuencia anterior el abandono: Apolonio deja a su hija y termina con los piratas venden a Tarsia. Podemos identificar aquí un auténtico cuento maravilloso: la niña huérfana es asediada por la madrastra; Tarsia es otra Blancanieves.

Se produce una importante ruptura espacial y dos acontecimientos en acción paralela. El cambio de escenario dará lugar a la no simultaneidad de los personajes en el espacio: al no encuentro de Apolonio con su hija. El acontecimiento final de este bloque es también comienzo del siguiente:

E.3. El burdel. Los piratas venden a Tarsia es el comienzo de este bloque que terminará con Tarsia actúa en la plaza pública.

Sin embargo, la historia de esta joven no termina aquí, se prolonga más allá hasta encontrarse con su padre y en su final se funde con el bloque narrativo que llamamos reencuentro.

\section{F) El regreso}

Paralelo en el tiempo con parte de la estancia de Tarsia en el burdel tiene lugar el regreso del héroe. De nuevo el hilo narrativo vuelve a ser llevado por la figura del personaje principal. Este bloque se inicia con la llegada de Apolonio a Tarso y se cierra cuando Apolonio, queriendo dejarse morir, emprende un viaje de vuelta a Tiro. El destino interviene de nuevo y el mar fuerza un cambio de rumbo que termina 
en la ciudad de Mitilene. Desde el momento en que el héroe llega a esta ciudad se produce la coincidencia espacial de dos personajes antes separados: Apolonio y Tarsia. Esta coincidencia espacial dará lugar al comienzo del siguiente bloque narrativo:

\section{G) El reencuentro}

El reencuentro en esta novela será doble, como doble fue la separación, por tanto se manifiesta en dos microbloques:

G.1. La hija. Se inicia esta microsecuencia cuando Atenágoras ve la nave de Apolonio y termina con el reconocimiento de la hija por el héroe. Se produce aquí la intersección de la historia de Tarsia con la de Apolonio y se cierra definitivamente el bloque narrativo Tarsia.

Un sueño y el personaje central serán la unión entre este bloque y el siguiente.

G.2. La esposa. Se inicia con la aparición en sueños de quendam angelico habitu y termina con: la esposa reconoce a Apolonio.

Se produce otra intersección, la de la línea narrativa que seguía a la esposa de Apolonio y la que sigue a este mismo. Aquí se cierra definitivamente el bloque narrativo resurrección.

Una vez se han producido los encuentros, el resto de la historia carece prácticamente de interés, la línea narrativa seguirá el resurgimiento del héroe, pero ya con mucha aceleración. Todo ello se engloba en un bloque narrativo que carece de elementos fundamentales para el desarrollo de la historia y que podemos denominar:

\section{H) Final feliz ${ }^{27}$}

\subsubsection{Resumen bloques narrativos}

Tenemos pues ocho bloques narrativos que se suceden unos a otros y quedan unidos de la siguiente manera:

27 El desenlace, pese al tono generalmente trágico de toda la obra, será feliz. Aristóteles señala que la representación puede tener un final trágico o feliz: el primero es 
A) EL INCESTO, situación introductoria, da lugar al planteamiento de

B) LA PRUEBA, la solución de ésta causará

C) LA HUIDA, que cesará gracias a la Fortuna (muerte de Antíoco) y esta muerte y una sucesión de acontecimientos ocurridos con anterioridad ocasionarán que Apolonio herede el reino de Antíoco, lo que provocará

D) LA SEPARACIÓN de la esposa, y la iniciativa del protagonista provocará

E) LA SEPARACIÓN de la hija (aquí intercalada está la historia de Tarsia); la iniciativa (la voluntad del héroe) provoca

F) EL REGRESO y de nuevo la actuación de la Fortuna ocasiona

G) EL REENCUENTRO con la hija y EL REENCUENTRO con la esposa. $\mathrm{El}$ regreso al reino y

H) EL FINAL FELIZ no son más que la consecuencia normal y esperada del final de la novela.

\section{CONCLUSIONES}

Con este examen creemos que se ha visto de una forma más evidente que la historia está bastante mejor motivada de lo que en general se ha considerado.

La fortuna hace su aparición en momentos importantes como son los encuentros y reencuentros y en la separación de Apolonio y su esposa. Sin embargo, el encuentro que da lugar a toda la aventura, el encuentro con Antíoco, no tiene por qué ser interpretado como un encuentro fortuito. Apolonio, como todos los príncipes, ha de solicitar la mano de la princesa, pero sabe el riesgo al que se expone y así se lo

propio de la tragedia más bella, el segundo de la Comedia: «En segundo lugar está la estructuración considerada por algunos la primera, la cual tiene estructura doble, como la Odisea, y termina de manera contraria para los buenos y los malvados... Pero éste no es el placer que debe esperarse de la tragedia, sino que más bien es propio de la comedia». (Poet. 1453a22-36). Este final feliz es una concesión del autor de la novela al público que obtiene así la satisfacción que desea. "Y parece ser la primera por la flojedad del público, pues los poetas, al componer, se pliegan al deseo de los espectadores» (Poet. 1453a33-34). 
dice al rey cuando éste se lo pregunta (nosti nuptiarum conditionem?... Noui et ad portae fastigium uidi. cap. $4^{28}$ ). Pese a todo, Apolonio decide arriesgarse.

Otro momento importante en el que no interviene la fortuna es la separación entre padre e hija. Apolonio deja a Tarsia con Estranguilio y Dionisia por voluntad propia y nada realmente le fuerza al abandono. De hecho y ya en el texto, el autor culpa a Apolonio de las desgracias de Tarsia, así cuando ésta va a ser asesinada por Teófilo y pregunta quid peccaui, ut manu tua innocens uirgo moriar?, obtiene del uillicus de Dionisia la siguiente respuesa tu nihil peccasti, sed pater tuus peccauit... qui te cum magna pecunia et uestimentis regalibus reliquit Stranguillione et Dionysiadi (cap. 31).

Los reencuentros son producto de la fortuna, con un debilitamiento cada vez mayor de la lógica casual evidenciado en la introducción de un deux ex machina (la visión angélica de la que hemos hablado) para justificar el último viaje y reconocimiento ${ }^{29}$.

No es raro que la motivación se debilite en el final de la historia cuando el autor está llegando a una parte de ésta por la que ya no siente tanto interés, el suspense ha perdido su sentido, de aquí en adelante ya se sabe lo que va a suceder.

El análisis realizado nos permite apreciar cómo la estructura de la novela es episódica: alrededor del héroe se centran los acontecimientos principales. El hilo de la narración está conducido por un solo personaje, el héroe, que se relaciona con el resto de los personajes de relieve, protagonistas de su propia subfábula. Por otro lado, ias diferentes subfábulas de la historia quedan perfectamente insertas en la fábula principal que es la que narra la vida de Apolonio.

Las líneas de unión entre las diferentes secuencias de acontecimientos son de diversa índole, pero su combinación puede resultar al lector adecuada a lo que él espera del género, se adapta perfectamente al horizonte de expectativas de un lector que, como el nuestro, aprecia el sabor folklórico que sin duda posee la historia; por otro lado, la intromisión esporádica del azar en las decisiones e iniciativas de los hombres no hace sino conferir a este relato una mayor sensación de verosimilitud, de semejanza con la vida real.

28 Citamos por la edición de Schmeling (1988).

29 Aristóteles previene sobre el uso de este recurso: «Así pues, es evidente que el desenlace de la fábula debe producirse de la fábula misma, y no como en la Medea, de una máquina... (Poet. 1454b). 
Por último, nuestro análisis por acontecimientos y bloques narrativos nos permite delimitar ahora el argumento de la novela:

Un príncipe acude a solicitar la mano de una princesa que vive, secretamente, en incesto con su padre; éste plantea al pretendiente un enigma, lo soluciona pero es engañado y, perseguido a muerte por el rey, tiene que huir de su patria, toma esposa y, muerto su perseguidor, hereda su reino; en el viaje para hacerse cargo de éste, tiene una hija, se separa de su esposa e hija, que pasan desventuras y, después de mucho tiempo, vuelve a reencontrarse con ambas; regresa a su reino en donde vive feliz hasta su muerte.

\section{Referencias bibliográficas}

Aristóteles (1974). Poética de Aristóteles. Ed. trilingüe por V. García Yebra. Madrid: Gredos.

BAL, M. (1987). Teoría de la narrativa. Una introducción a la narratología. Madrid: Cátedra.

BAJTIN, M. (1989). Teoría y estética de la novela. Madrid: Taurus.

BARTHES, R. (1974). «Introducción al análisis estructural de los relatos». En Análisis estructural del relato, Comunicaciones, Buenos Aires, 9-43.

Bremond, C. (1974). «La lógica de los posibles narrativos». En Análisis estructural del relato..., Buenos Aires, 87-109.

GARCIA GuAL, C. (1988). Los orígenes de la novela. Madrid: Istmo.

Greimas, A. J. (1976). Semántica estructural. Madrid: Gredos.

HÄAG, TH. (1983). The novel in antiquity. Berkeley-Los Ángeles: Basil Blackwell.

HENDRICKS, W. (1976). Semiología del discurso literario. Madrid: Cátedra.

KAYSER, N. (1985). Interpretación y análisis de la obra literaria. Madrid: Gredos.

Propp, V. (1985). Morfología del cuento. Madrid: Akal.

SCHMELING, G. (1988). Historia Apollonii regis Tyri. Leipzig: Teubner.

SEGRE, C. (1985). Principios de análisis del texto literario. Barcelona: Crítica.

Todorov, T. (1974). «Las categorías del relato literario». En Análisis estructural del relato..., Buenos Aires, 155-192.

Tomachevsky, B. (1982). Teoría de la literatura. Madrid: Akal.

WALSH, P. G. (1970). The roman novel. Cambridge University Press.

JAUss, H. R. (1976). La literatura como provocación. Barcelona. 